\title{
STATUS OF ION BEAM MODIFICATION AND ANALYSIS OF MATERIALS AT STU MTF
}

\author{
Jozef DOBROVODSKÝ, Dušan VAŇA, Matúš BEŇO, Anna ZÁVACKÁ, \\ Martin MUŠKA, Róbert RIEDLMAJER \\ SLOVAK UNIVERSITY OF TECHNOLOGY IN BRATISLAVA, \\ FACULTY OF MATERIALS SCIENCE AND TECHNOLOGY IN TRNAVA, \\ ADVANCED TECHNOLOGIES RESEARCH INSTITUTE, \\ Ulica JÁNA BotTu 2781/25, 91724 TRNAVA, SLOVAK REPUBLIC \\ e-mail: jozef.dobrovodsky@stuba.sk,dusan.vana@stuba.sk, matus.beno@stuba.sk, \\ anna.zavacka@stuba.sk, martin.muska@stuba.sk, robert.riedlmajer@stuba.sk \\ Received: 04.06.2018, Accepted: 21.01.2019, Published: 29.01.2019
}

\begin{abstract}
The new Ion Beam Centre (IBC) equipped with $6 \mathrm{MV}$ tandem ion accelerator and $500 \mathrm{kV}$ ion implanter systems was built at the Slovak University of Technology, Faculty of Materials Science and Technology (STU MTF). The facility provides Ion Beam Modification of Materials (IBMM) and Ion Beam Analysis (IBA), which includes Rutherford Backscattering Spectrometry (RBS), Particle Induced X-ray Analysis (PIXE), Elastic Recoil Spectrometry (ERDA) and Nuclear Reaction Analysis (NRA). Presented are selected experimental procedures carried out in the IBC during the first year of operation. They present examples of a typical IBA performed, such as thin film characterisation in $\mathrm{nm}$ to tens of $\mu \mathrm{m}$ range, elemental depth profiles and sensitivity to the light elements enhancement by non-Rutherford cross-section regime application along with the crystalline sample channelling spectra and boron content measurement.
\end{abstract}

\section{Key words}

Ion Beam Modification, Ion Beam Analysis, ion implantation, RBS, PIXE, NRA, ERDA, channeling

\section{INTRODUCTION}

Selecting the most appropriate ion beam parameters (type of ion, energy, ion flux, fluence (dose), beam size, etc.), the ion-solid interaction can be adjusted, from weak or slightly perturbative (ideal for the nondestructive analysis (1)), to strong (able to substantially modify the material structure, composition and properties).

Particle accelerators have proven to be competitive devices in the condensed matter scientific and technological field, and have allowed evolving the applied branches such as Ion 
Beam Analysis and Ion Beam Modification of Material. Even at STU, efforts have been made to engage in this global process since the beginning of this process development (2). However, the result of this effort corresponded to the real material and other conditions for research at the University at that time. Thanks to the new IBC at STU MTF within the Advanced Technology Research Institute (ATRI) as part of the CAMBO Trnava Scientific Park, it is now possible to continue to use IBA and IBMM in material research at STU at the latest technological level.

The summary of IBC Trnava first-year of operation, including examples of the IBA and IBMM experiments performed, is presented.

\section{EXPERIMENTAL}

The $6 \mathrm{MV}$ Tandetron tandem ion accelerator and the $500 \mathrm{kV}$ ion implanter have been in operation since the beginning of the year 2016 . The facility provides ion beams in a wide range of energies - from $40 \mathrm{kV}$ to tens $\mathrm{MeV}$, beam currents - from sub nA to mA; virtually all elements from hydrogen to bismuth can be accelerated. Accelerator systems with the $90^{\circ}$ mass separating magnets in the injection section provides isotopically pure beams. The maximum achievable energies are: $12 \mathrm{MeV}$ for proton, $18 \mathrm{MeV}$ for $\mathrm{He}^{2+}$ and e.g. $54 \mathrm{MeV}$ for $\mathrm{Au}^{8+}$ beams, depending on the extracted ion charge state. Long-term stable and energy-narrow $\left(10^{-3}-10^{-4}\right)$ ion beams have been achieved.

Pure and carbon-free vacuum in all the vacuum parts of both accelerator systems ensure oil-free pumping systems, based on the scroll and turbo-molecular vacuum pumps. Secure, reliable and efficient operation of accelerators as well of analytical and implantation end stations are covered by their central computer control systems. Since operating parameters, settings and accelerator states are recorded in the computer's memory, the repetition of the accelerator setups starting from the ion source, through already used beam parameters is considerable simplified.

The implantation end stations are available for the synthesis and modification of materials at both accelerators. Samples of a diameter up to 4 inches at the Tandetron and up to 8 inches at the implanter can be treated at the room temperature, at the controlled elevated temperature up to $800{ }^{\circ} \mathrm{C}$, or cooled down to LN2 temperature (4).

The following analytical methods are available for material analysis (5):

- RBS - typical application is depth profiling of heavy elements at light substrate, depth resolution few nm

- RBS/C - RBS in channelling or blocking mode - provides information about crystalline material, .e.g. the amount and depth distribution of lattice disorder; location of the impurity atoms at the lattice site, the damage/defects of the crystal, etc. (6)

- ERDA - based on the detection of energy and velocity/mass of atoms that are knocked out from the sample by incoming heavy ions. The currently installed ERDA system is an extension of the RBS measurement system and is limited to the light element depth profiling

- PIXE - the accelerated particles knock electrons out of the occupied energy levels, what leads to the production and emission of characteristic X-rays. Specific energy peaks identify the sample elements at the sensitivity of ppm, as the K. L, and M X-rays are a fingerprint of each element (3).

- NRA - products of the ion beam induced nuclear reactions are detected. The light isotope concentration depth profiles (typically of elements: H, D, Li, B, C, O, and F) in complex matrices can be measured at a sensitivity of $10 \mathrm{ppm}$.

- PIGE - Particle Induced Gamma ray Emission - is a special case of the NRA when prompt gamma rays are detected, which are emitted from the nuclei's that are excited after the nuclear reaction induced by the charged particle. 
Overview of IBA techniques and their typical applications and detection capabilities is summarized in Table 1.

Table 1: Synopsis of the IBA techniques, their detection capability and main applications (1)

\begin{tabular}{|c|c|c|c|}
\hline Main Application & & Relevant Techniques & Detection Capability \\
\hline Materials Science & \multirow{7}{*}{ 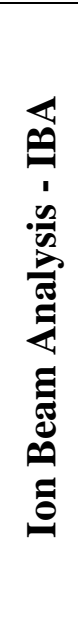 } & $\begin{array}{l}\text { Rutherford Backscattering } \\
\text { Spectrometry (RBS) }\end{array}$ & $Z>1$ \\
\hline $\begin{array}{c}\text { Archeometry and Cultural } \\
\text { Heritages }\end{array}$ & & $\begin{array}{l}\text { Elastic Recoil Detection } \\
\text { Analysis (ERDA) }\end{array}$ & $\begin{array}{c}\mathrm{Z}<17 \\
\text { (typically including } \mathrm{H} \text { ) }\end{array}$ \\
\hline $\begin{array}{l}\text { Earth and Environmental } \\
\text { Science }\end{array}$ & & $\begin{array}{l}\text { Particle Induced X-ray } \\
\text { Emission (PIXE) }\end{array}$ & $\mathrm{Z}>11$ \\
\hline Biological Sciences & & $\begin{array}{l}\text { Nuclear Reaction Analyses } \\
\text { (NRA) }\end{array}$ & $\begin{array}{c}\mathrm{Z}<17 \\
\text { (often for } \mathrm{C}, \mathrm{N}, \mathrm{O} \text { and } \\
\text { isotopes) }\end{array}$ \\
\hline $\begin{array}{l}\text { Nuclear Safety and } \\
\text { Radioprotection }\end{array}$ & & $\begin{array}{l}\text { Particle Induced Gamma ray } \\
\text { Emission (PIGE) }\end{array}$ & $\begin{array}{c}\mathrm{Z}<17 \\
(\mathrm{Li}, \mathrm{B}, \mathrm{F}, \mathrm{Na}, \mathrm{Mg}, \mathrm{Al}, \mathrm{Si})\end{array}$ \\
\hline $\begin{array}{l}\text { Fundamental Nuclear and } \\
\text { Atomic Physics }\end{array}$ & & $\begin{array}{l}\text { Scanning Transmission Ion } \\
\text { Microscopy (STIM) }\end{array}$ & sample density \\
\hline Forensic Science & & Ionoluminescence (IL) & defects and sample structure \\
\hline
\end{tabular}

The Ion Beam Center was presented in more detail elsewhere [4]. A brief overview of the first year facility operation, in particular with respect to the major achievements of the device parameters regarding modification and analysis, is given bellow. Not all the values are listed chronologically, but rather only extreme ones are given.

\section{Ion Beam Modification of Materials}

The summary of the first year of IBMM running at the ATRI facilities is as follows:

$500 \mathrm{kV}$ implanter: elements $\mathrm{H}, \mathrm{B}, \mathrm{N}, \mathrm{P}, \mathrm{Ne}, \mathrm{Ar}, \mathrm{Cu}, \mathrm{Ga}, \mathrm{Fe}, \mathrm{Co}, \mathrm{W}$, including 57Fe isotope were accelerated from natural elemental abundance sources in the energy range from $30 \mathrm{keV}$ to $400 \mathrm{keV}$. The efficiency of the beam transport from the ion source to the sample depends on the ion optics of the system, which is dependent on the ion beam energy. The maximum beam current from the ion source on the high-voltage terminal was $4 \mathrm{~mA}(\mathrm{Ar}, \mathrm{N})$, while a beam current of $0.5 \mathrm{~mA}(\mathrm{Co})$ and at least $1.6 \mu \mathrm{A}(\mathrm{W}, \mathrm{Fe})$ were achieved in the implantation chamber. Applied implantation doses varied from $1 \times 10^{16} \mathrm{at} / \mathrm{cm}^{2}$ to the maximum of $8 \times 10^{17} \mathrm{at} / \mathrm{cm}^{2}(\mathrm{Co})$.

6 MV Tandetron: elements $\mathrm{H}, \mathrm{He}, \mathrm{B}, \mathrm{C}, \mathrm{Si}, \mathrm{Cu}, \mathrm{Ni}, \mathrm{W}$ and $\mathrm{Au}$ have been accelerated in the energy range from $480 \mathrm{keV}(\mathrm{H})$ to $54 \mathrm{MeV}(\mathrm{Au})$. The maximum beam current of $10 \mu \mathrm{A}(\mathrm{H}, \mathrm{Si})$ or $13 \mu \mathrm{A}(\mathrm{Cu})$ was at the implantation end-station. During $25 \mathrm{MeV} \mathrm{Cu}$ implantation, a $325 \mathrm{Watt}$ beam power was reached. Applied implantation fluences varied from very low $1 \times 10^{7} \mathrm{at} / \mathrm{cm}^{2}$ $(54 \mathrm{MeV} \mathrm{Au})$ to $3 \times 10^{16} \mathrm{at} / \mathrm{cm}^{2}$. Implantation of $30 \mathrm{MeV} \mathrm{Cu}$ was performed at an elevated temperature of $700{ }^{\circ} \mathrm{C}$.

\section{Ion Beam Analysis}

RBS: Most of the RBS analyses were carried out in a standard RBS mode, i.e. using a He beam in the energy range from $600 \mathrm{keV}$ to $2 \mathrm{MeV}$, while up to $10 \mathrm{MeV}$ beam was used to characterize the thick layers. Thin films of an equivalent thickness less than $1 \mathrm{~nm}$ to the thickness of $12 \mu \mathrm{m}$ were characterized. 
Examples of the $\mathrm{Au}$ and $\mathrm{Cu}$ thin layers thickness on the Si substrate RBS measurements are given in Fig. 1 and Fig. 2. RBS was used to calibrate the thin layer deposition device because it gives the absolute value of thickness in units of at $/ \mathrm{cm}^{2}$.

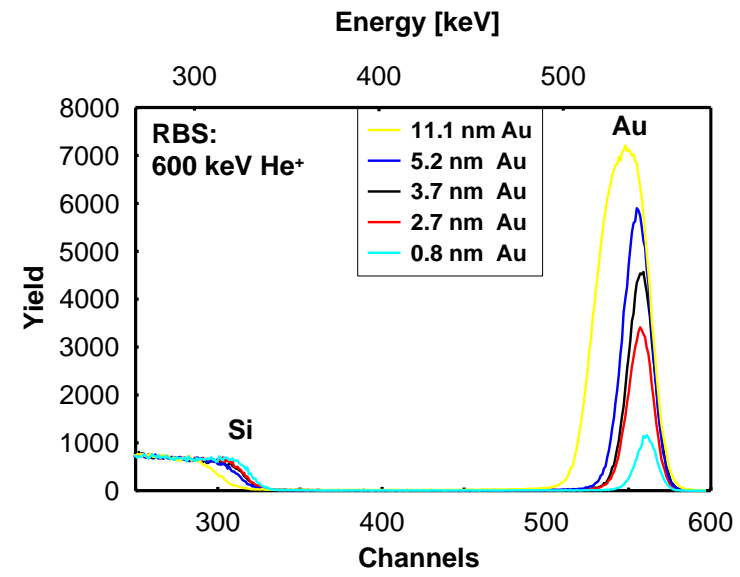

Fig. 1 RBS spectra of various Au layer thicknesses on Si substrate in nm range were performed by the $600 \mathrm{keV}$ He beam. For thickness calibration, a $60^{\circ}$ sample tilt and $170^{\circ}$ backscattering angle were used

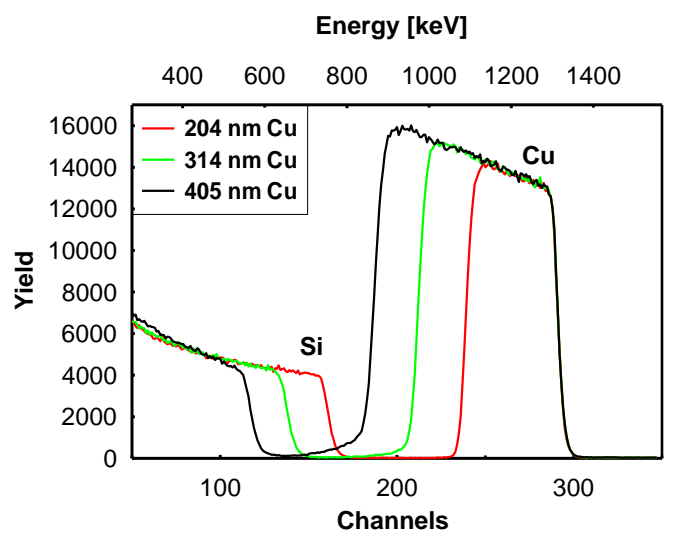

Fig. 2 RBS spectra of different Cu layer thicknesses on Si substrate in the hundreds nm range were measured using the $1700 \mathrm{keV}$ He beam. For thickness calibration, a normal ion beam incident (no sample tilt) and $170^{\circ}$ RBS angle was used

Application of $2 \mathrm{MeV} \mathrm{H}$ increased the depth of the RBS analysis. Fig. 3 documents the RBS spectra of $12 \mu \mathrm{m}$ thick TiN layer, which enables sample stoichiometry determination.

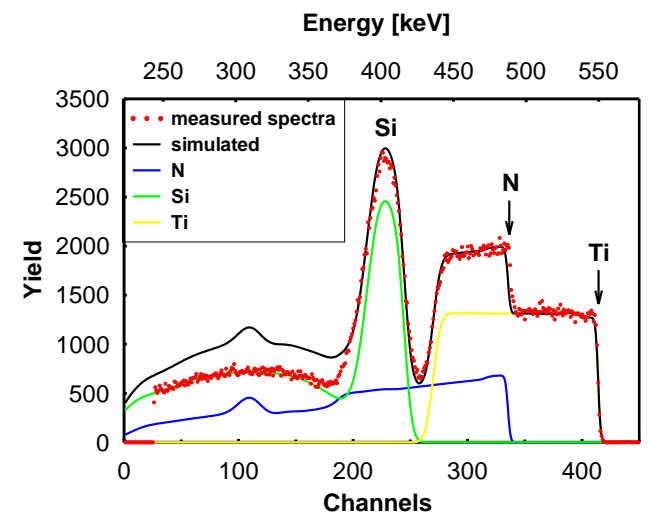

Fig. 3 RBS spectra of a $12 \mu \mathrm{m}$ TiN layer on a Si substrate measurement. A normal $2 \mathrm{MeV} H$ beam incident and $170^{\circ} R B S$ angle was used. Stoichiometry of Ti $(0.55) N(0.45)$ was revealed 
The non-Rutherford back scattering regime was used to enhance the $\mathrm{C}, \mathrm{N}$ and $\mathrm{O}$ signal during measurement. Compared to the standard RBS, improved sensitivity for light elements by one to two orders of magnitude can be reached, as can be seen in Fig 4.

(a)

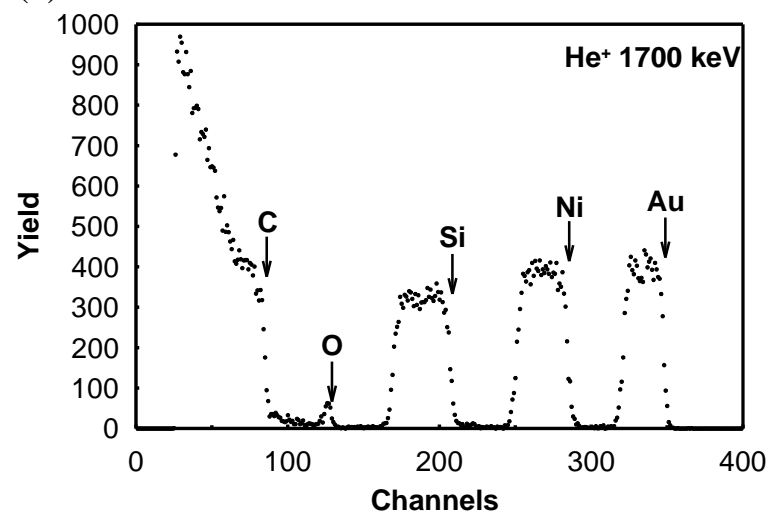

b)

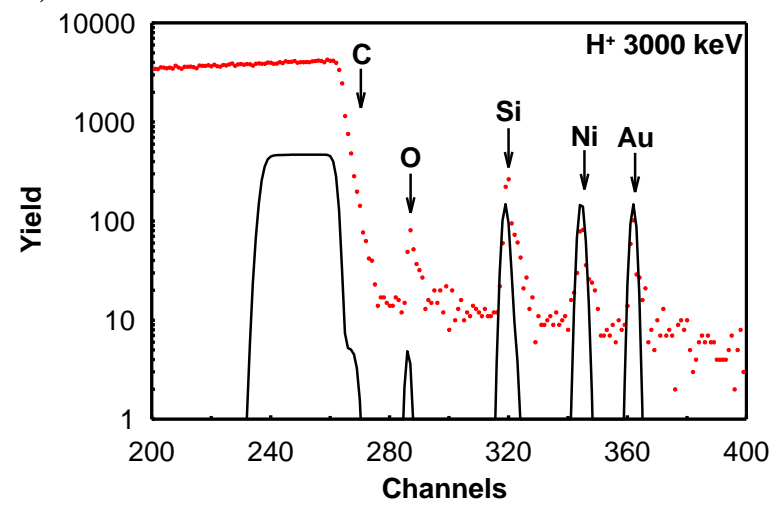

(c)

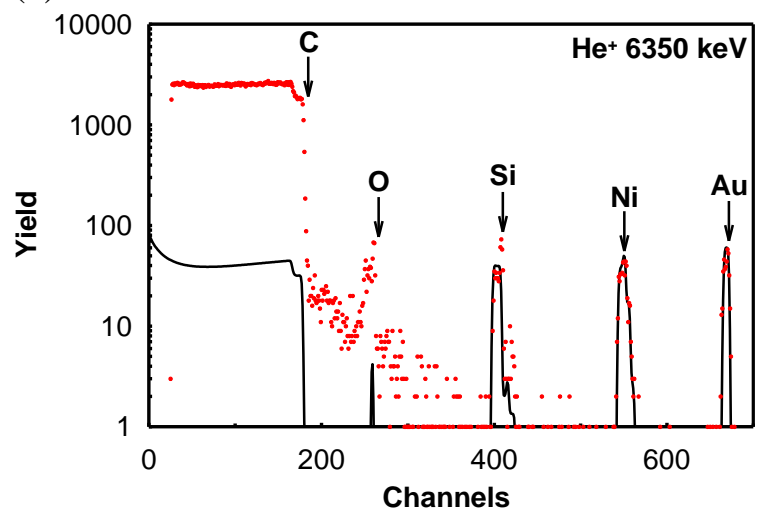

d)

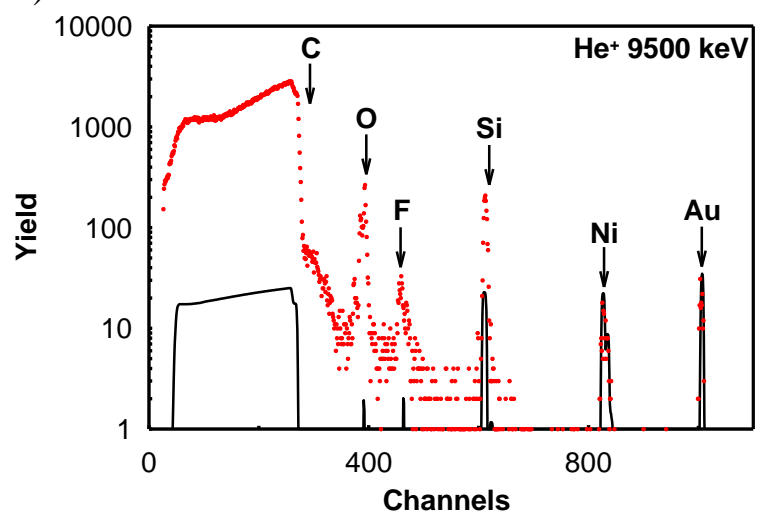

Fig. 4 The use of non-Rutherford cross section for carbon and oxygen signal enhancement at elevated beam energies. Carbon signal enhancement relative to the standard $1.7 \mathrm{MeV} \mathrm{He} \mathrm{RBS} \mathrm{(a)} \mathrm{is} \mathrm{one} \mathrm{order}$ of magnitude using $3 \mathrm{MeV} \mathrm{H}$ beam (b), 1.5 orders of magnitude for $6.35 \mathrm{MeV} \mathrm{He} \mathrm{beam} \mathrm{(c)} \mathrm{and} \mathrm{two}$ orders of magnitude using $9.5 \mathrm{MeV}$ He beams $(d)$

Examples of the $\mathrm{MoS}_{2}$ and TiNC films interdiffusion on $\mathrm{Al}_{2} \mathrm{O}_{3}$ and $\mathrm{Si}$ substrates are shown in Fig. 5 and Fig. 6.

RBS/C: The crystal sample alignment with the specific crystallographic axes and the channeling spectra measurement is demanding task. This requires typically to measure hundreds of RBS spectra. The first step was to preform automation of the measurement process. Automation of the basic evaluation of the channeling spectra measurements will follow in the near future. An example of the Si crystalline channeling spectra was presented in (7). 
(a)

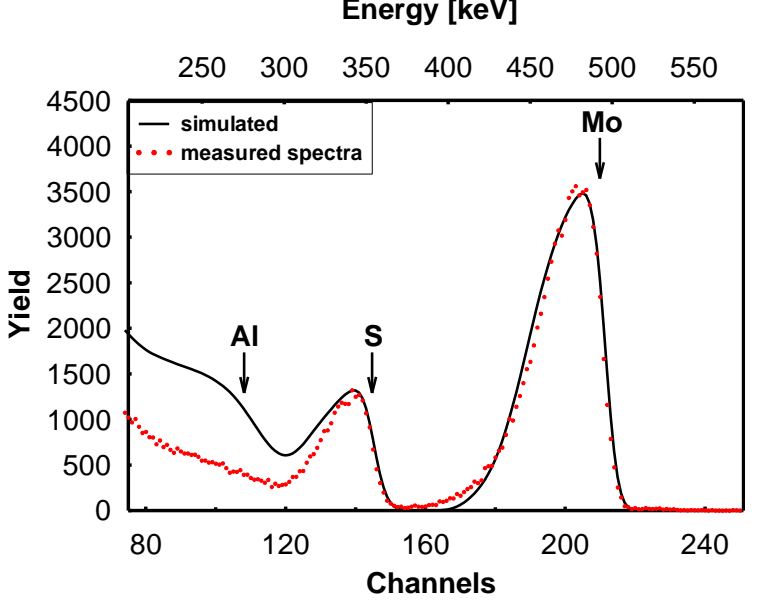

(b)

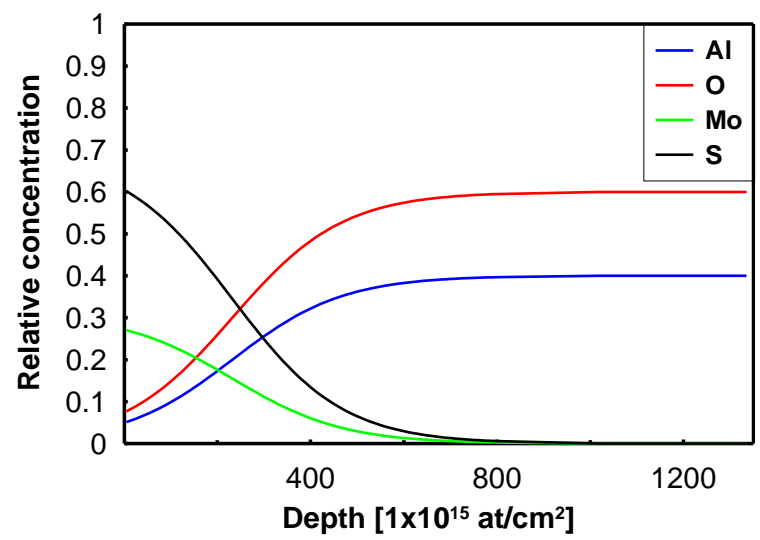

Fig. 5 Interdiffusion of a $\mathrm{MoS}_{2}$ film on a $\mathrm{Al}_{2} \mathrm{O}_{3}$ substrate. A $600 \mathrm{keV}$ He RBS spectrum (a) and acquired sample element concentration depth profiles $(b)$

(a)

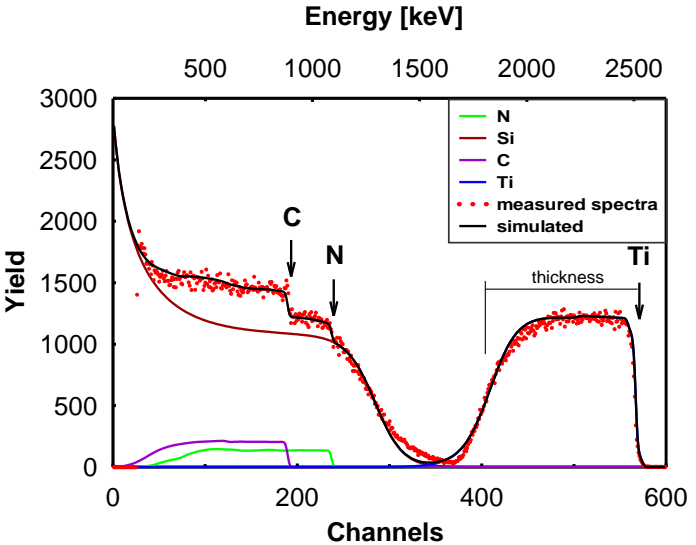

(b)

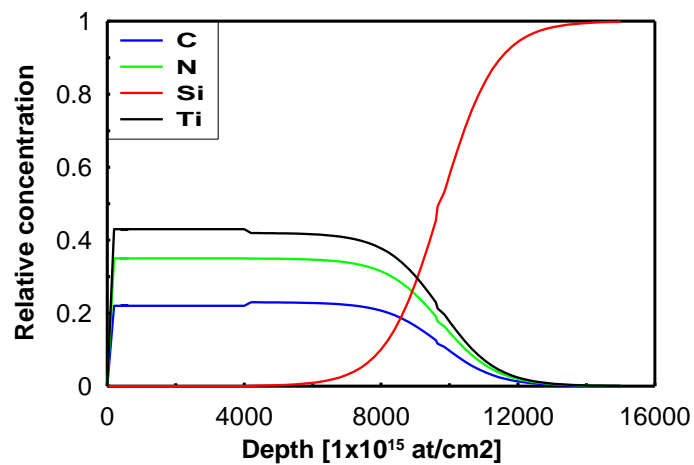

Fig. 6 Interdiffusion of a TiNC film on a Si substrate. A 3.5 MeV He RBS spectrum (a), normal beam incident, $R B S$ angle $170^{\circ}$ and acquired sample element concentration depth profiles (b)

PIXE: PIXE measurements of solid samples are done routinely [7]. There are ongoing activities to improve the quantitative evaluation of PIXE measurements, without the use of special reference samples. Since it is a complex problem, a detailed and comprehensive PIXE X-ray detection system characterization is required. Recently, the PIXE setup was adapted to measure aerosol filters.

NRA: Depending on the nuclear reaction product, for NRA analysis either a/ $\gamma$ rays are detected by $\mathrm{LaBr}$ scintillation or alternatively by HPGe detectors, or b/ protons or alpha particles are detected by silicon charged particle detector. For the ${ }^{31} \mathrm{P}(\alpha, p){ }^{34} \mathrm{~S},{ }^{10} \mathrm{~B}(\alpha, \mathrm{p}){ }^{13} \mathrm{C},{ }^{11} \mathrm{~B}(\mathrm{p}, \alpha){ }^{8} \mathrm{Be}$ nuclear reactions, the standard RBS/ERDA experimental setup was used. As an example, the alpha particle spectra from ${ }^{11} \mathrm{~B}(\mathrm{p}, \alpha)^{8} \mathrm{Be}$ reaction taken by $750 \mathrm{H}^{+}$beam from samples with various boron content is given in Fig. 7. Energy of the emitted $\alpha$ particles was $3.7 \mathrm{MeV}$. 


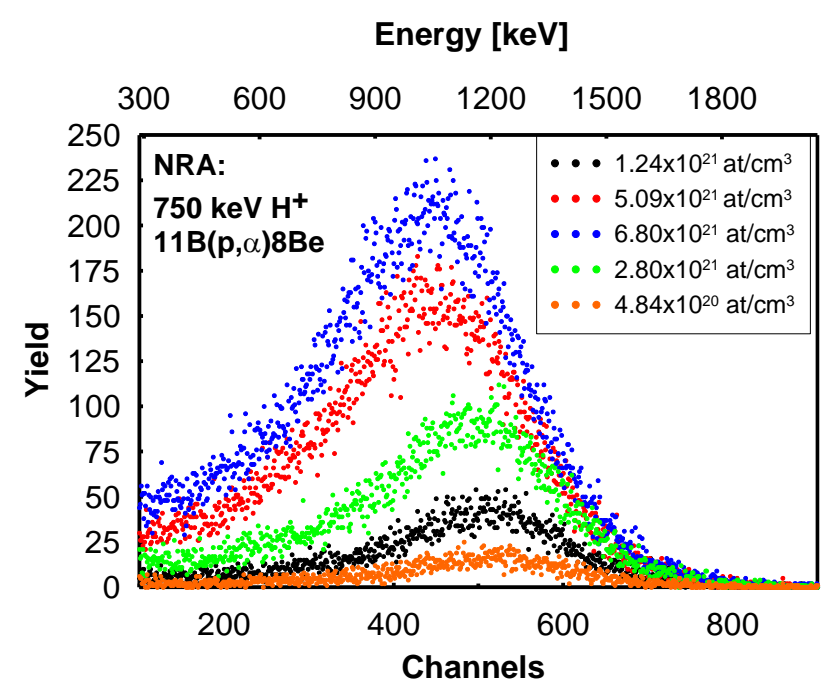

Fig. 7 Measurement of boron content in carbon samples. $A 750 \mathrm{keV}$ proton beam, incident angel $0^{\circ}$ and detection angle $160^{\circ}$ was used. After filtering out the backscattered protons by $6 \mu$ m thick kapton foil, the energy spectra of alpha particles $-o f^{11} B(p, \alpha)^{8} B e$ nuclear reaction product were recorded.

Each color represents an individual spectrum taken from a sample with a specific boron concentration.

In order to achieve the $(p, \gamma)$ or $(\alpha, \gamma)$ nuclear reaction analysis, an extension of the IBA experimental setup was needed (7). A small single-sample electrically isolated chamber was added to the IBA chamber. The experimental assembly allows the ion beam energy sweeping by applying high voltage on the sample holder. So far, the ${ }^{19} \mathrm{~F}(\mathrm{p}, \alpha \gamma){ }^{16} \mathrm{O},{ }^{27} \mathrm{Al}(\mathrm{p}, \gamma){ }^{28} \mathrm{Si}$, ${ }^{22} \mathrm{Ne}(\mathrm{p}, \gamma)^{23} \mathrm{Na}$ and ${ }^{20} \mathrm{Ne}(\mathrm{p}, \gamma)^{21} \mathrm{Na}$ resonance nuclear reactions have been used.

ERDA: The hydrogen depth profiles were measured by ERDA. An example of the hydrogen depth concentration profiles was given in (7).

The SIMNRA simulation program [8] was used for the RBS and ERDA spectra evaluation.

\section{CONCLUSION}

After mastering the new IBC experimental devices, including implantation and analytical systems, a number of initial preparatory and verification experiments were carried out. On the basis of the presented illustration of the experimental work performed during the first year after commissioning the Ion Beam Centre facility, we can state that the operation of complex experimental facility was fully mastered. In addition to the energy calibration of ion accelerators and related systems, modification of materials, ion implantation and the whole range of the available ion beam based analytical methods was brought to life and began to be regularly used for research purposes.

\section{Acknowledgement}

This research output was supported by the Ministry of Education, Science, Research and Sport of the Slovak Republic under the project of "Development of STU research infrastructure" No. 003STU-2-3/2016 and Scientific Grant Agency of the Ministry of Education of the Slovak Republic and the Slovak Academy of Sciences No. VEGA-1/0219/16. 


\section{References:}

1. A. ZUCCHIATTI, A. REDONDO-CUBERO. 2014. Nucl. Instr. Meth. B 33148.

2. P. KOVÁČ, P., M. PAVLOVIČ and J. DOBROVODSKÝ. 1994. A 0.9-MV Accelerator for Materials Research at the STU Bratislava. Nucl. Instr. Meth. Phys. Res. B 85749.

3. INSTRUMENTATION FOR PIXE AND RBS IAEA, IAEA-TECDOC-1190, VIENNA, 2000.

4. P. NOGA, J. DOBROVODSKÝ, D. VAŇA, M. BEŇO, A. ZÁVACKÁ, M. MUŠKA, R. HALGAŠ, S. MINÁRIK, R. RIEDLMAJER. 2017. Nucl. Instr. Meth. Phys. Res. B 409, 264, https://doi.org/10.1016/j.nimb.2017.04.051

5. M. NASTASI, J.W. MAYER, Y. WANG. 2014. Ion Beam Analysis - Fundamental and Applications, CRC Press.

6. A. VANTOMME. 2016. "50 years of ion channeling in materials science". Nucl. Instr. Meth. B 371, pp. 12-26.

7. J. DOBROVODSKÝ, M. BEŇO, D. VAŇA, P. BEZÁK, P. NOGA. 2018. The first year operation experience with Ion Beam Analysis at the new STU. Nucl. Instr. Meth. Phys. Res. B. https://doi.org/10.1016/j.nimb.2018.10.006

8. SIMNRA home page, http://home.mpcdf.mpg.de/ mam/. 